\title{
Triangulation Experiences in Educational Settings: Rethinking the Concept
}

\author{
M. Teresa Sirvent ${ }^{*}$, Ana Clara Monteverde, Marcela Fabiana Agulló
}

Faculty of Philosophy and Letters, School of Educational Sciences Area, University of Buenos Aires, Buenos Aires, Argentina.

\begin{abstract}
How to cite this paper: M. Teresa Sirvent, Ana Clara Monteverde, Marcela Fabiana Agulló. (2022). Triangulation Experiences in Educational Settings: Rethinking the Concept. The Educational Review, USA 6(1), 1-9.

DOI: 10.26855/er.2022.01.001
\end{abstract}

Received: November 21, 2021

Accepted: December 26, 2021

Published: January 20, 2022

Corresponding author: M. Teresa Sirvent, Faculty of Philosophy and Letters, School of Educational Sciences Area, University of Buenos Aires, Buenos Aires, Argentina.

Email: m_sirvent@yahoo.com

\begin{abstract}
This article presents contributions and challenges regarding triangulation processes performed in social and educational research, on the basis of a completed project at: University of Buenos Aires-Argentina, Faculty of Philosophy and Letters/School of Educational Sciences Area. This research project refers to a network analysis of conditions which either ease or block education claims, derived from individual and social groups educational needs upon a 'permanent education' in a lifelong context. This research is based on educational poverty diagnoses around young adults and the adult population from Argentina. This paper unravels - through different work lines - a 'black box' originated as a consequence of historical, social, individual processes, accounting for the re-creation or breakdown of these poverty situations, advance or cumulative advantage educational principles, specially focused on a triangulation and combined approach. In other words, such methodological strategy suggested, will be described fulfil and consists of the methodological convergence of different ways of building science processes in a educational-social area: a Verificative Approach (traditionally associated with quantitative methods), a Conceptual Generative Approach (traditionally associated with qualitative methods), and a Participatory Praxis Approach (traditionally associated with participatory research methods). By virtue of this methodological perspective, it will highlight what it may be considered as innovative contributions and challenges linked to a network analysis of conditions which either ease or block education claims, derived from individual and social groups educational needs upon a 'permanent education' in a lifelong context. Let us start by mentioning "how to make triangulation processes" as regards to our project and secondly, we will address a variety of theoretical issues about integrated triangulation. In essence, these potential approaches refer to an old discussion on the possibilities of a combined paradigm in which different epistemological viewpoints of the world are mixed, the social backgrounds, and the construction of scientific knowledge in such a social field.
\end{abstract}

\section{Keywords}

Integrated Triangulation, Methodological Convergence, Permanent Education

\section{Methodological and contextual aspects of the research project}

This present project began in 1985 in the context of the University of Buenos Aires, Argentina, Philosophy and Letters Faculty/School and it is based on a "permanent educational perspective" which covers both the school resources 
and other resources far beyond school, too. Along these lines, permanent education can be analyzed as an everlasting necessity and a right of all population.

The former claim regarding the access to education is understood as a process of social and individual construction. In order to study this matter, it must be done a triple settlement of the educational demand: social, potential and effective. All this should be done providing that potential demand may change into a social and effective one. Potential demands refer to a group of population 15 years and over, with different educational needs that can be afforded by the educational system or not. Effective demands, refer to those educational aspirations that are properly satisfied in either young adults or adult schools, at a deliberated time point. Social demands, refer to an organized and collective educational claims and needs way of expression, that the members of a social group seek to implement through institutional and/or public decisions (Sirvent, 1999a; Sirvent, Toubes, Santos, Llosa, \& Lomagno, 2007).

A remarkable aspect of these three concepts is that the social demand can introduce a collective analysis unit, unlike potential and effective demands based on individual analysis units.

The starting point of the investigation relies on the census study about the education in poverty situations of population 15 years and over Argentina 2010, whoever attended school but dropped out.

This situation is analyzed through the concept: Educational Risk Level and Cumulative Advance Educational Principle (and its validation), which states that the population that has the most initial education is the one that demands the most education throughout life, as of 'permanent education' (Sirvent, 1992; Sirvent, 1996; Sirvent, 1999a; Sirvent \& Llosa, 2001). We intend to fathom and reveal, through different research work-lines, such 'black box' of historical, social, and individual affairs accounting for the re-creation or breakdown of poverty situations.

As a result of important investigation procedures together with all empirical evidence collected so far, it may be concluded that the demand for permanent education refers to a complex socio-historical process that implies the conversion of a potential demand into effective demand and into social demand. Likewise, socio-historical key factors were identified that were processed into individual or group levels, which works as learning conditions that may ease or block such educational processes. This research work drives along-in 2014, the build up of a network of factors and processes that are articulated as conditions for the construction of individual and social demand for permanent education.

The building of that network, set multiple relationships among all the results coming from those different research work-lines of our whole project, showing grounds for a new theory and a new theoretical construction, which enables us to understand the aforementioned phenomena by different lines of interpretation.

We assume that scientific investigation of social matters supposes a building process in which a "real object" becomes "scientific object". In this sense, the researcher, in the midst of reflexive operations, "builds the mentioned scientific object" from an epistemological and theoretical perspective (Rigal Sirvent, 2021). The theoretical and methodological complexity of the object under study has led to the deployment of the project around five axes or core ideas, aimed at different aspects of our study object (Figure 1). This challenge is based each research work-line results, and it is summarized in the following chart:

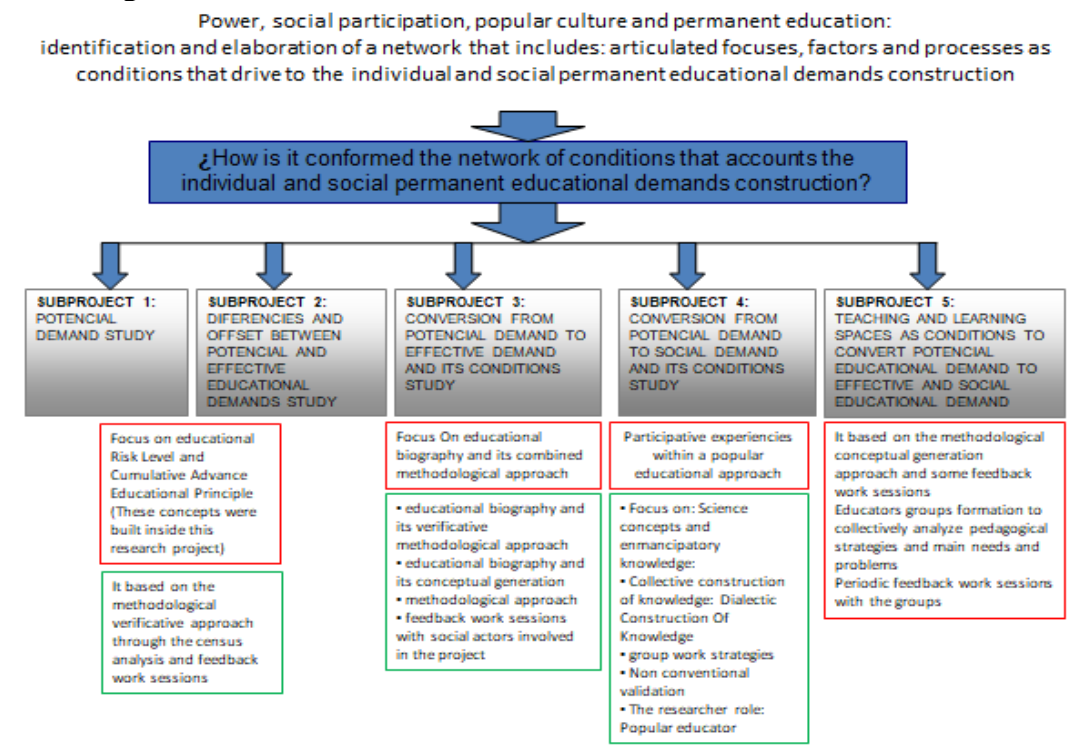

Figure 1. Research work-lines of the project. 


\section{Concerning of different ways of doing social science}

The methodological strategy related to build empirical evidence, according to the complexity of the study $o b$ ject-problem and the research work-lines already mentioned; it is held in the combination of the following ways of doing social science: verificative approach (usually commented on the resolutions of quantitative proceedings), conceptual generation approach (usually commented on qualitative and interpretative proceeding resolutions), and participatory praxis approach.

It is acknowledged that this innovative perspective goes further the quantity/quality dyad.

Additionally, it is universally understood that different ways of performing social sciences research are not only part of a group of research techniques and empirical information analysis, or just a merely differentiation between numbers and qualities to represent social phenomenon; but it is necessary to attend different ways of developing and conceiving "social sciences research", going further the traditional dichotomy in the research field, between quantitative vs qualitative methods. (Rigal Sirvent, 2021)

Firstly, the innovation takes place as regards to articulation between epistemological dimensions of social sciences paradigms; research logic postulates and its methodological procedures, regarding different ways of doing social sciences. Secondly, the innovation takes place as regards to the designation of the three ways or forms of social researching, as well as, the verificative approach or form, the conceptual generation approach or form and participatory approach or form (Sirvent, 1999b; Sirvent, 2010; Sirvent, Rigal, Llosa, \& Sarlé, 2012; Rigal \& Sirvent, 2021), as it will be later broadened. Third, an integrated triangulation process was defined to establish links between the different sub-projects, which made it possible to find five focal points, which are developed later in this article.

These three ways of doing social science, alongside the possible methodological convergence (Sirvent, 1999c; Sirvent, 2010c), allow a new integrated vision overcoming those exclusive, contrary or antagonistic traditional ways.

A Convergence of Methodologies means a priority in the contemporary social epistemology, consisting of a plural and methodological outlook. We specially work on the three ways of doing social science, the role of the social groups involved in the construction of knowledge and in its validation with the social groups involved.

Whenever the topic 'different ways of doing social science' is reached, we must refer to a diversity of methodological resolutions of the social research practices and their daily duties, understanding these duties as tasks of a genuine craft made practice, who presents, amongst other implications: different ways of understanding the conditions of knowledge production; different ways of integrate theoretical data corpus and empirical data corpus, different links between the researcher and the researched social object, different aims in the social research process, different strategies in the social research process.

From this point of view, instead of discussing ideas about the use of survey techniques and the analysis of empirical information, defining a systematic approach based on the presence or absence of qualities and numbers, we set a discussion on the basis of epistemological traditions that social science paradigms hold and which work as foundation in its methodological definition: a Positivist Tradition, the Hermeneutic Tradition, and the Critical Social Theory (Sirvent, 1999b; Sirvent, 2010; Sirvent, Rigal, Llosa, \& Sarlé, 2012; Sirvent \& Rigal, 2012, Rigal Sirvent, 2021). As we were remarking above, and to revert the dual social traditional methods (qualitative-quantitative methods), the nomination that we have built, is the following:

- Verificative approach or form: Traditionally called quantitative methods. It is based on historical positivist epistemology dimensions and focused on the positivist paradigm in social science. It has held the pre-eminence of the physical-natural sciences methods as a unique acceptable course of social knowledge construction

- Conceptual generative approach or form: Traditionally called qualitative methods. It is based on the epistemology dimensions of hermeneutic paradigm, and establishes, contrary to positivism, social specificity of the world. The social phenomena are conceived as a strong structure of meanings derived from social interactions. It opposes methodological monism in the construction of a social reality and denies scientific impartiality.

- Participatory praxis approach or form: It is epistemologically based on the Critical Social Theory, it emphasizes central participatory processes of the subject of study and in most investigations decisions and collective constructions of scientific knowledge, that points to the transformation of reality. The praxis notion, a vertebral concept of the epistemological dimension, accepts the human being only knows how much he creates and transforms reality.

Therefore, assuming the challenge of these three approaches combinations will take into account that each research form- above-mentioned-involves a logic and epistemological strategy, carried out by distinctive methodological operations. This pushes the motion to highlight the main epistemological research basis and the logic and methodological decisions linked to every social science process and, consequently, linked to its full integration and convergence. In 
other words, this triangulation process based on three approaches comes from different research designs.

\section{Stages of the research project}

In order to start building our net, we should face different stages, that is:

First stage: We identificate key focuses which may contribute as a starting point to articulate the different sub-projects (See chart pt. 1). Key focuses are considered as: Those situations that articulate links among the different sub-projects.

The Key focuses identified:

1. Educational Risk Level and Cumulative Advance Educational Principle

2. Conversion from Potential to Effective demand

3. Conversion from Potential to Social demand

4. Pedagogical strategies and sustenance of the Effective demand

5. "Multiple poverties" situations and demand for a better Permanent Education

Second stage: Intersection of links or theoretical knots and identification of possible articulations among sub-projects, with clear reasons and objective statements (Figure 2).

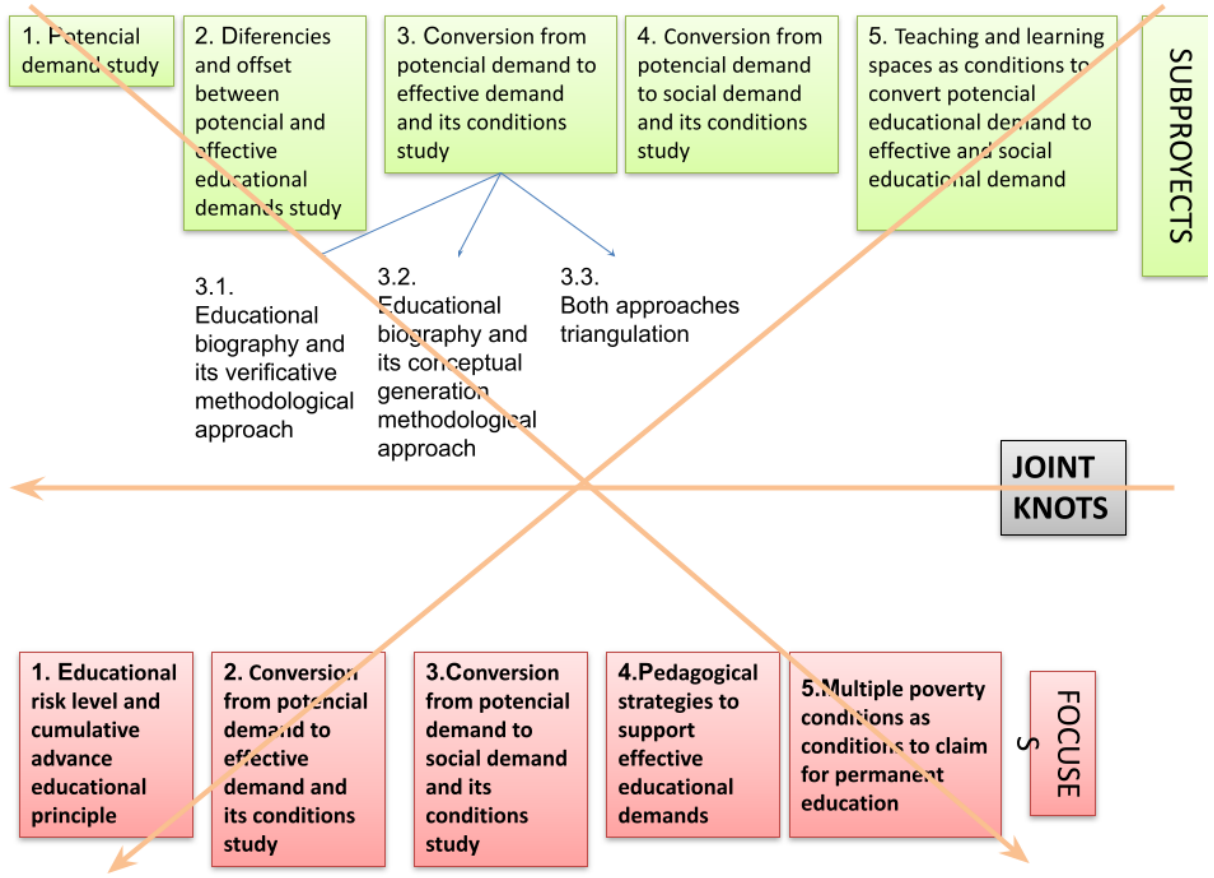

Figure 2. Intersection of links or theoretical knots and articulations among sub-projects.

Third stage: Socialization of Key focuses 1 and 2. This stage is guided toward the inclusion of each sub-project team so as to check and complete their fulfillment.

Fourth Stage: Inter- relationships, links and reasons that show the integration of other elements in the network.

In order to fully understand our triangulation processes, it will be rewarding to illustrate it "extensively".

\section{Methodological examples of Key Focus 2: From Potential to Effective demand}

The origin of this articulation perspective sets the basis of certain triangulation key points among sub-projects 3.1 and 3.2, related to an accurate treatment of academic -educational biographies (the analysis of these biographies was an important part of the research) about the changing-conversion- from Potential to Effective Demand; specifically described in sub-project 3.3 of triangulation. Other sub-projects also bring different theoretical knots and articulations (Figure 3).

These key points in triangulation can be read as elements of a net of social conditions, revealing Permanent Education demands, as presented below: 


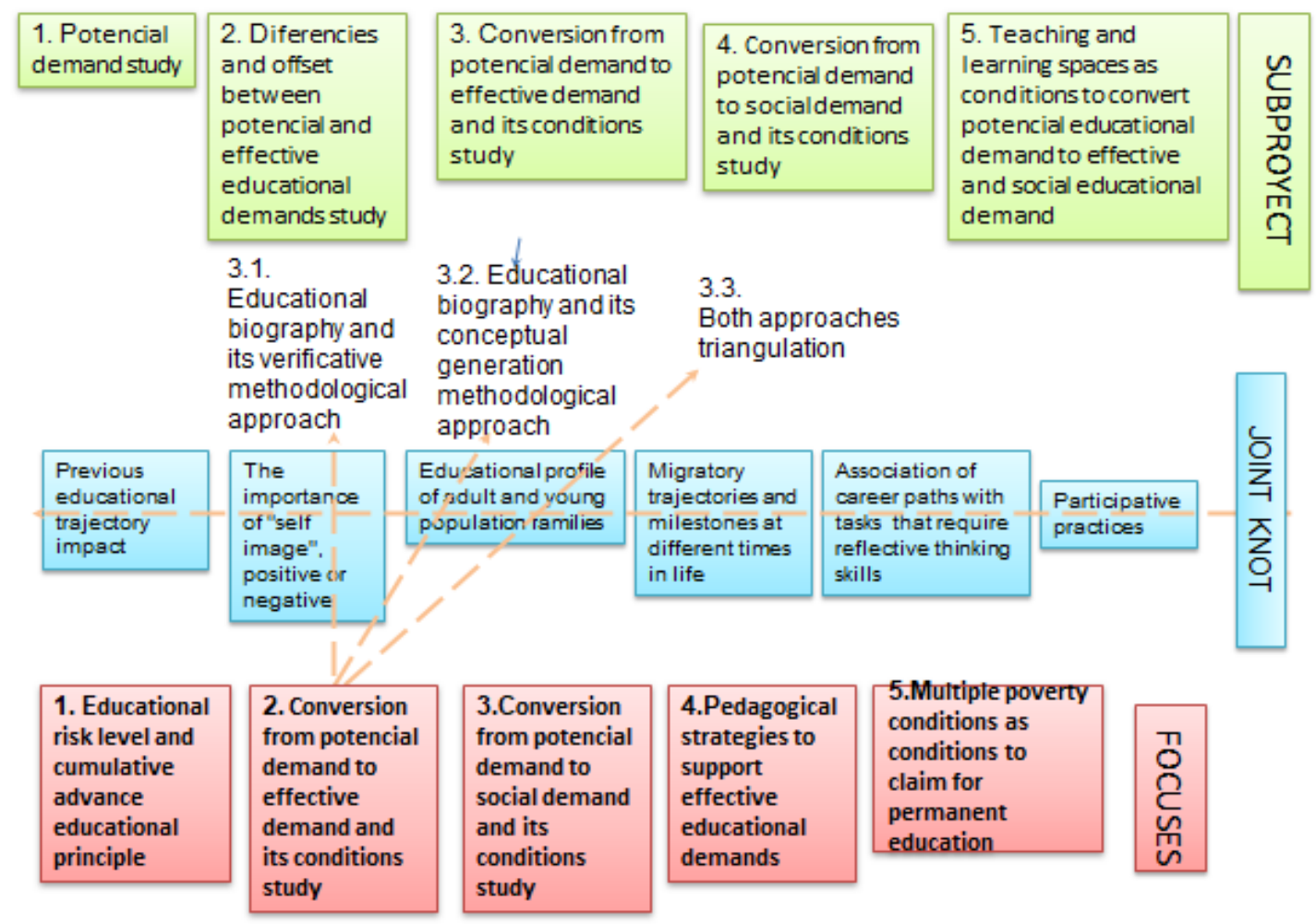

Figure 3. Articulation knots and their definition in Sub-projects 3.1 and 3.2

1) Educational trajectory impacts on the construction of the everlasting educational demands. We can see it in the articulation between statistic standards belonging to an only variable in educational trajectory from sub-project 3.1(focused on accurate verifying treatments of educational biographies), and, categories about conditions of educational trajectory, from sub-project 3.2 (focused on the conceptual generative treatment of educational biographies). In sub-project 3.1, the study of elementary educational trajectory according to (academic) cycle length finds relevant that "Here the average of scholar people who end primary school (leaving aside the delay product of absences and constant interruptions) is higher". In sub-project 3.2, inner processing of an "Impoverishing truncated start" is commonly seen. It refers to a determined plot about irregular trajectory coming from primary school, lack of knowledge, a negative trainee self-image and an inadequate representation of scholar places, which plays a harmful role in later construction procedures of ADULT EDUCATIONAL SYSTEM-EDJA in Spanish- demands in "backward accumulation paths"

2) Self-image relevance (positive or negative), is found in statistics of a behavior articulation linked to a variable of educational trajectory, with context conditions, especially the building of a self-image as a trainee or as an apprentice. Proportional to results, people returning to classes-adult schools- hold a better trajectory unlike those who do not. It is possible to think these trajectories helped the production of self-apprentices images, while certain context conditions. It is clear that there is a link to the representation of scholar places, and the "EDJA spaces" orientate the construction of educational demands.

3) Composition and educational level of younger /adult families. In statistical analysis carried out by sub product 3.1, a considerable weight in familiar trajectories is regularly seen in conformity with educational level terms. Besides, effective demands (of those who return to school) have increased the number of positive percentages and educational structure of families according to Educational Risk Level indexes. Over the years, people have coexisted with families who end high school which can be related to contextual conditions, clearly expressed in sub-project 3.2.

4) Migratory trajectory and migration landmarks in different moments of adult life. Along verificative treatments of educational biographies we may find a predictable strength in the variable of migratory trajectory in relation to the dependent variable: who returns to school is not "a migrant”. These statistics' results disagree with hypothetical 
cases of certain antecedents which showed positive effects of migration. By means of conceptual generative treatment of educational biographies, the processing of psychosocial migration (compulsory migration specially) and its negative impact in the educational trajectory. It could be defined that sub-project 3.1 population would be compulsory migrations situations rather than elective ones.

5) The relevance of Job trajectory associated with responsibilities which demand reflexive thoughts abilities. In the verificative treatment we see (among the realization of effective demands for more and better permanent education) an increasing job trajectory with essential tasks which involve a significant challenge to reflexive thoughts abilities. Through conceptual generative treatment of educational biographies, a temporal evolution of certain job trajectories, where different issue performances that include reflexive thoughts (math and literacy skills, observation, classification, abstraction, etc.) have improved orientation toward young and adult education spaces, as satisfactory "possible and proper" facing educational aspirations.

6) Participatory practices. In the case of a participatory trajectory variable, although there is no evidence of influences expected in sub-project 3.1, an incidence of social participation (in former periods) influences school activities returns. In those analyzed events which rely on the conceptual treatment, it was acknowledged the participation of social organizations and political parties, which motivated demand for educational constructions related to the EDJA-adult educational system in our country.

7) The objectification -analysis- of aspects of their own educational biography. It has been seen in feedback sessions -achieved in the combination of a participatory style research sessions-, suggestive reflexive own learnings which may reflect self-esteem changes, accounting for stimulation of a positive self-image.

\section{Final thoughts about the: Elaboration of the Conditions Network aimed to the construction of educational demands, belonging to Permanent Education}

Throughout conceptual and methodological construction of such network in our project, we arrive to some reflections so as to go on thinking, that is:

In a report written in 2013, in a congress set by the Instituto de Investigaciones en Ciencias de la Educación de la Facultad de Filosofía y Letras in our sub-projects mentioned, we point out a dialectical association between the starting point of UBACYT project - an educational risk situation of young/adult population that don't assist to school, (subprojects 1 and 2), and the finishing line, "a pedagogical path" (sub-project 5), saying: "To finish this presentation on sub-project 5, referring to conditions in teaching and learning spaces which establishes the alteration of potential, social and effective, whose experiences show the fight against educational poverty, with higher vulnerable situations.

Everything present in this paper makes visible the possibility to go deeper into that network conditions which interacts on one another by reproducing or even surpassing the "determinism" of the beginning of acumulative educational advancement, and thinking over future teaching interventions that, as it has been previously stated, are 'a condition' on their own.

Analysis results from 2010 census distinguish some variables which determine that part of the educational risk in the adult population, in this project UBACYT already studied, where positive contextual conditions appear to allow the change of potential into effective demands.

\section{Some theoretical frameworks for triangulation procedures in educational investigations}

\section{Recovering the concept of: Multiple triangulation}

Mix investigation methods have arisen historically from the tension in quantitative and qualitative proceedings, being included in triangulation discussions, specially, as regards relevant property of their usage in suitable social phenomena.

The word triangulation, refers to triangles, mathematical figures that refer to geometry and trigonometry issues. All in all, in this area we make reference-for example- to see the distance between a settled point based on triangle, an angle and two sides, three angles/sides or two sides and an angle. This term reached disciplines, originally not conceived, just as Social Sciences.

Denzin (1970) has paid close attention to the triangulation phenomenon. He confirms that triangulation concerns the possibility to mix data, researchers, methods, theory, or all factors simultaneously, turning them into a multiple triangulation.

During the 70 century, Denzin set different ways of using such triangulation procedures, organizing possibilities and alternatives to embrace the most suitable one. For example, data triangulation layout, which takes into account a wide range of spaces, lapses and subjects of study. 
Another illustration based on triangulation refers to the role of the 'researchers', incorporating multiple observers to collect the same data instead of entrusting the task to just one.

A third proceeding, method triangulation, makes reference to the usage of more than one method at a time, or the combination of more than one technique so as to get and analyze data information deeply. Normally, this last category helps to understand triangulation to the full extent.

During the 90's decade Kimchi and other specialists accept Denzin's definition. It is pointed out like a procedure to grant reliability of results, since they may present a higher theoretical strength, in contrast to others who use a unique method (Donolo, 2009).

Blaikie (1991) confirms that a triangulation priority, as an investigation strategy, is applicable to the validation increase, as well as, the reduction of statistical bias issues. However, an investigation strategy also aims at the expansion of complex comprehensions grounded on what is being studied.

Cowman defines it as a multiple methods combination to address the phenomenon more properly, while Morse describes methodological triangulation as the simultaneous usage of two methods, usually the quantitative method and qualitative one so as to address the same research. When a singular method investigation is inadequate, triangulation is used for the sake of arriving at a more accurate understanding of the results of the investigation.

Vasilachis de Gialdino (1992), resumed the concept 'methodological and theory combination with data and researchers involved'. He adds the latter concept may be intra/inter-methodological and claims the main profit such combinations brings, is about the ability to overcome bias issues and limits held in their integration. Thus, triangulation will give a comprehensive overview on data collected, weaknesses identification and the necessity to supplementary approaches.

Sautu, R, argues the importance of methodological combinations, pointing out the emphasis upon investigation objects which establish which are the most accurate methodologies. Moreover, Sautu (2003: 53) explains "under this position framework, it is possible to articulate and coordinate specific objects which answer methods associated with quantity and quality methodology. That is to say, triangulation or methodological combinations may take place at an objective construction level, clearly expressed as a theoretical construction used in method choices". Currently methodological combinations or mix investigations (Bryman, 2006/Cameron, 2011/Creswell, 2011/Creswell, Plano-Clark, Gutaman \& anson, 2003/Migiro \& Mangani, 2010; Pole, 2007; Rocco, Bliss, Gallager, \& Perez-Prado, 2003; Tedile \& Tashakory, 2006) basically understand the possibility of integration into social sciences approaches-i.e., verificative method, Conceptual generation, and Participatory praxis-in investigation designs for better comprehension of the social phenomena.

As it was previously warned, there would exist an agreement on the way of triangulation as if it helps to get different images from the context analyzed, in other words, to expand empirical evidence construction regarding social research.

In our academic community, Sirvent (2008) will understand triangulation as the methodological process based on an epistemological perspective, and looks for epistemology convergence (triangulation), logics and investigational methods.

Likewise, in her participatory praxis research, she introduces the concept of "methodological triangulation in situ" to the extent that this way of doing science provides different methodological combinations between the studies of the same object in spaces for confrontation. The possibility of a complete study-object is due to the articulation of two different types of knowledge — quotidian knowledge and scientific knowledge-in that "triangulation in situ" approach where feedback sessions are achieved.

In the course of UBACYT's last reports-UBACYT is the name that the University gives to research projects, a multiple triangulation took place because of data, methods and researchers triangulation in either intra and inter sub-projects, attempting to catch a more holistic and complex project portrait of our project.

Inter triangulation sets cross control of domestic consistency or credibility as long as intra triangulation tests external validity (Jick, 1979).

\section{Rethinking the Concept: Integrated triangulation}

In this final report of our research, the construction of key factors network articulated the conditions of social, individual demands for a permanent education, implies the setting of numerous possible relations between results attained of several investigation work lines from sub-projects, making available the fact of understanding such phenomenon from different points of view.

In Rosemberg, Menti (2007), accounting for his methodological framing within their investigation about the study of social interactions and language developments, underlined the importance of mixed methodology procedures in educational areas: "such combination may imply triangulation, convergence, and the integration of simultaneous methodologies (qualitative-quantitative) in order to understand various dimensions from the studied object, and give answers to 
research questions".

Mix methodologies, different approaches, convergences and integrations seem concepts within methodological educational works and in areas where several approaches, perspectives, "voices” and tools are committed.

In this sense, up to this point, it has emerged that the concept of triangulation could be refreshed in accordance with the construction of a theoretical-methodological strategy.

In this way, we would be defining our analytical research process as an integrated triangulation process, that is to say, along a goal which produces a new epistemological object qualified to set solid links among sub-projects; since it has been arrived at a conceptual plot articulating theoretical perspectives based on five approaches and their respective articulating knots.

So that, the study of the Educational Risk Level and Cumulative Advance Educational Principle, the conversion of potential into effective educational demands, the conversion of potential into social demands, pedagogical strategies to support effective demands, and multiple poverty conditions as conditions to claim for permanent education.

From this perspective, already mentioned, integrated triangulation advantages in investigation processes should be easily perceived, such as:

$\square \quad$ Higher epistemological strength: Integrated triangulation allows the construction of new epistemological concepts, new accurate categories illustrating study phenomena.

$\square \quad$ Higher methodological strength: Integrated triangulation eased the motion of basic methodological strategies and investigation techniques for attachments in a more consistent field with the construction of the study object.

$\square \quad$ Higher creativity, flexibility and analysis production together with result collections, and sensible variation degrees not noticeable with just an only way of doing science, discovering atypical phenomena, innovating conceptual framings, theory summaries, proximity between investigator and object of study.

$\square \quad$ Higher approach upon a holistic way of doing social science in education which contributes to a deeper interpretation and comprehension of the object of study.

$\square \quad$ Higher disciplinary availability within the research project team: A project has been accomplished based on multi-disciplinary professionals according to the academic productive coexistence of different professions in our team. Higher validity of results, acknowledging permanent education demands implies complex psychological processes of construction at a group, social and individual levels.

\section{Integrated triangulation in educational researches: contributions, challenges and possible scenarios}

All along the path of this report on educational investigations, it has been stated that collective knowledge constructions among the research team lead to contributions and challenges display regarding the strategic usage of such integrated triangulation, such as:

$\checkmark$ Integrated triangulation suggests the setting of new scenarios and the building methodological processes which provide potential relationships, such are link cases-in our project, for instance, and knot articulations between sub-projects; giving place to new correspondences through methods, interferences and results, all this by means of different investigation work lines so as to fully understand the object of study.

$\checkmark$ Integrated triangulation enables us to join link results together, so, preceded by research designs which contribute to different paradigms respected to epistemological, logical and methodological dimensions. This perspective can be compared with a rainbow picture which reflects several colours that describe it as such. "It is" in as far as all dimensions "are" and coexist...

$\checkmark$ Integrated triangulation can be clearly analyzed according to key focus networks and processes articulated as the construction of individual and social claims as regards permanent education; as a result of tangible profits deriving from inner multiple triangulation procedures.

$\checkmark$ Integrated triangulation is a contextualized approach (it is located at present times), which allows for showing, illustrating, showing, analyzing and sharing what has been under investigation.

$\checkmark$ Integrated triangulation performed in our project makes relevant the fact of paradigm convergences, an almost eternal debt of socio-educational investigation fields. In this sense, this project works as the kickoff to go on with epistemological, inter-paradigm discussion which overcame dualisms and took place in pluralities.

Our politic-educational times, specially, claim epistemological buildings establishing different methodology structures, giving importance to a holistic phenomenon.

It is worth recalling that the exact etymology of the word 'investigation' derives from investigation, which means 'to trace', follow a path to discover something unknown throughout a vestigium, trace or remnant. In order to trace prints, 
reveal, discover, it is advisable to consider plural paths which may set changes in praxis searches that interpret data in a critical and reflexive way. From this viewpoint, deductive paradigm will not be sentenced due to harsh toughness or procedural accuracy, contrary to subjectivity constituency; notwithstanding, the intention depends on horizons getting closer to an ontological view and it also depends on phenomenon analysis subjected to epistemological, methodological and logical perspectives.

\section{References}

Blaikie, N. W. H. (1991). A critique of the use of triangulation in social research. Quality and Quantity, 25, 115-136.

Cowman, S. (1993). Triangulation: a means of reconciliation in nursing research. Journal of Advanced Nursing, 18: 788-792.

Denzin, N. K. (1970). Sociological Methods. A Sourcebook. Chicago, IL: Aldine Publishing Company.

Donolo, D. S. (2009). Triangulation: Procedures introduced at new methodologies. Digital Universitary Magazine, 10(8), art. 53.

Kimchi, J., Polivka, B., Stevenson, J. S. (1991). Triangulation: Operational Definitions. Methodology. Corner. Rev. Nursing Research, 40(6).

Morse, J. M. (1991). Approaches to Qualitative-Quantitative Methodological Triangulation. Methodology. Corner. Rev. Nursing Research, 40(1).

Rigal, L. and Sirvent, M. T. (2021). Social and educational methodology: Different paths into knowledge production. Miño y Dávila Editors, Buenos Aires, Argentina. Manuscript under revision.

Rosemberg, C. and Menti, A. (2014). Theoretical and methodological aspects on interactions and opportunities in language development. Educational notebooks. Pages 8-9. Pelotas. Brasil.

Sautu, R. (2003). Everything is theory: Objectives and methods in research works. Buenos Aires, Lumiere Editors.

Sirvent, María Teresa, Llosa, Sandra Mabel, Stein, Alejandra. (2018). Epistemological and methodological dimensions on an autobiographical research study, the methodological triangulation on biographic research: Contributions and challenges on studying educational demands throughout life. Buenos Aires University - IICE/Philosophy and Letters Faculty. Presented at VIII International Congress on Biographic Research. Sao Paulo September $17^{\text {th }}-20^{\text {th }}$, 2018. Book Collection Publishers, VIII CIPA.

Vasilachis de Gialdino, I. (1992). Qualitative Methods I: Theoretical and methodological problems. Buenos Aires. CEAL Editors. 